\title{
Ion-Molecule Reactions in Isopropanol: Implications for Its Radiolysis*
}

\author{
R. Gorden, Jr., and L. W. Sieck \\ Institute for Materials Research, National Bureau of Standards, Washington, D.C. 20234
}

(June 21, 1972)

\begin{abstract}
The photoionization of isopropanol $(i-\mathrm{PrOH})$ at $11.7 \mathrm{eV}$ has been investigated in the NBS high pressure photoionization mass spectrometer over the pressure range 0.1 to approximately 200 millitorr. The major primary ion, $\mathrm{CH}_{3} \mathrm{CHOH}^{+}$, reacts with a total rate coefficient of $1.1 \pm 0.1 \times 10^{-9} \mathrm{~cm}^{3} / \mathrm{mole}^{-}$ cule-s to yield mainly $(i$ - $\mathrm{PrOH}) \mathrm{H}^{+}$and $\mathrm{CH}_{3}\left(i-\mathrm{C}_{3} \mathrm{H}_{7}\right) \mathrm{COH}^{+}$. At pressures in excess of a few millitorr consecutive reactions of $(i-\mathrm{PrOH}) \mathrm{H}^{+}$and $\mathrm{CH}_{3}\left(i-\mathrm{C}_{3} \mathrm{H}_{7}\right) \mathrm{COH}^{+}$were also detected, including the overall dehydration process

$$
(i-\mathrm{PrOH}) \mathrm{H}^{+}+i-\mathrm{PrOH} \rightarrow \mathrm{H}_{2} \mathrm{O}+\left(i-\mathrm{C}_{3} \mathrm{H}_{7}\right)_{2} \mathrm{OH}^{+}
$$

These data are interpreted in light of a recent radiolysis study, and a thermal cationic chain mechanism for production of $\left(I-\mathrm{C}_{3} \mathrm{H}_{7}\right)_{2} \mathrm{O}$ consistent with those results is proposed. The value for the proton affinity of $\mathrm{SF}_{6}$ is also discussed in some detail.
\end{abstract}

Key words: Gas-phase kinetics; ion-molecule reactions; mass spectrometry; photoionization; proton affinity; radiolysis.

\section{Introduction}

Although the positive ion chemistry of the lower aliphatic alcohols has been extensively investigated in the vapor phase by mass spectrometric techniques, little is known concerning the reactions occurring in isopropanol $(i-\mathrm{PrOH})$ at higher densities. Beauchamp and co-workers [1], ${ }^{1}$ using electron impact ionization, have reported the only detailed study of this system, and although many reaction channels were

defined, those experiments were restricted to pressures less than approximately 0.1 millitorr. The vapor phase radiolysis of $i$ - $\mathrm{PrOH}$ has also been investigated by Van der Linde and Freeman [2] at high temperatures $(>400 \mathrm{~K})$ and pressures $(P>100$ torr $)$, and chemical evidence was obtained for the production of di-isopropyl ether via a cationic chain mechanism. To our knowledge, no other studies have been reported.

Recent studies in our laboratory [3] have revealed that rather dramatic changes may occur in the positive ion mechanism at pressures in excess of a few millitorr, and this information is often of fundamental importance in unraveling the behavior characteristic of much higher densities. In order to bridge the gap between the studies mentioned above and provide information which might be useful for interpreting

*This work was supported by the U.S. Atomic Energy Commission.

${ }^{1}$ Figures in brackets indicate the literature references at the end of this paper. the radiolysis data, we will report here a study of $i$-PrOH in the NBS high pressure photoionization mass spectrometer over the pressure range 0.1 to approximately 200 millitorr.

\section{Experimental Procedure}

All experiments were carried out with the NBS high pressure photoionization mass spectrometer described in detail elsewhere [4]. The methods used for deriving rate coefficients and other kinetic parameters have also been discussed previously [5].

\section{Results}

\subsection{Primary Mass Spectrum}

The following primary mass spectrum, given as percentages of the total ionization, was obtained when $i$-PrOH was photoionized at $106.7-104.8 \mathrm{~nm}$ (henceforth referred to as $11.7 \mathrm{eV}$ ); m/e 60 (parent) $(\sim 2 \%), \mathrm{m} / \mathrm{e} 59(\sim 3 \%), \mathrm{m} / \mathrm{e} 45(85 \%)$, and $\mathrm{m} / \mathrm{e} 44$ $(\sim 10 \%)$. Essentially the same composite spectrum may be derived from the data of Rafaey and Chupka [6] using their fractional photoionization cross-section curves and assuming a photon energy of $11.7 \mathrm{eV}$. The major primary ion produced in this system is the protonated acetaldehyde ion $(m / e 45)$, which results from simple $\mathrm{C}-\mathrm{C}$ cleavage in the $\alpha$ position: 


$$
\left(\mathrm{CH}_{3}\right)_{2} \mathrm{CHOH}^{+} \rightarrow \mathrm{CH}_{3} \mathrm{CHOH}^{+}+\mathrm{CH}_{3} .
$$

Elimination of methane to give $m / e 44$, which has been suggested to have the oxonium ion structure [6] also occurs to some extent,

$$
\left(\mathrm{CH}_{3}\right)_{2} \mathrm{CHOH}^{+*} \rightarrow \mathrm{CH}_{2} \mathrm{CHOH}^{+}+\mathrm{CH}_{4}
$$

as well as loss of $\mathrm{H}$ from the parent to give $m / e 59$, $\left(\mathrm{CH}_{3}\right)_{2} \mathrm{COH}^{+}$. The fractional yield of parent ions, $m / e$ 60, which do not dissociate at $11.7 \mathrm{eV}$ is quite small $(\leqslant 2 \%)$, reflecting the reported ease with which loss of $\mathrm{CH}_{3}$ and $\mathrm{CH}_{4}$ occurs from the molecular ion even at excitation energies only slightly in excess of the ionization threshold.

\subsection{Ion-Molecule Reactions-Reactions of Primary lons}

As the pressure in the ionization chamber is increased a number of reaction sequences are initiated by primary ions. The general behavior is displayed in figure 1 , which gives a representation of the composite mass spectrum obtained (major ions only) when $i$ - $\mathrm{PrOH}$ is photoionized at $11.7 \mathrm{eV}$ over the pressure range 0.1 to approximately 200 millitorr. When the fractional intensity of the major primary ion, $\mathrm{CH}_{3} \mathrm{CHOH}^{+}$, is plotted versus pressure over the range 0.1 to 2 millitorr a straight line is obtained for the decay curve from which an absolute rate coefficient of 1.1 $\pm 0.1 \times 10^{-9} \mathrm{~cm}^{3} /$ molecule-s may be derived for the process

$$
\begin{gathered}
\mathrm{CH}_{3} \mathrm{CHOH}^{+}+i \text {-PrOH } \rightarrow \text { Products other than } \\
\mathrm{CH}_{3} \mathrm{CHOH}^{+}
\end{gathered}
$$

Two major overall reaction channels are found for $\mathrm{CH}_{3} \mathrm{CHOH}^{+}$, proton transfer to yield $m / e$ 6l, $(i-$ $\mathrm{PrOH}) \mathrm{H}^{+}$, and condensation with loss of $\mathrm{H}_{2} \mathrm{O}$ to give $m / e \quad 87$ [most likely protonated methyl-isopropyl ketone]:

$$
\begin{array}{r}
\mathrm{CH}_{3} \mathrm{CHOH}^{+}+i-\mathrm{PrOH} \rightarrow(i-\mathrm{PrOH}) \mathrm{H}^{+}+\mathrm{CH}_{3} \mathrm{CHO} \\
\Delta H=-13[7] \\
\rightarrow(\mathrm{Me})(i-\mathrm{Pr}) \mathrm{COH}^{+}+\mathrm{H}_{2} \mathrm{O} \\
\Delta H=-38
\end{array}
$$

$[(\mathrm{Me})(i$-Pr $) \mathrm{CO}=$ methyl-isopropyl ketone $]$. In the low pressure range, under conditions where consecutive ion-molecule reactions are negligible (pressures $<1$ millitorr, fig. 1) the proton transfer reaction (process 4a) is favored by approximately a factor of three over process $4 \mathrm{~b}$. Processes $4 \mathrm{a}$ and $4 \mathrm{~b}$ have also been observed by Beauchamp and co-workers [la].

The other major primary ion, $m / e 44$, which is assumed to have the initial structure $\mathrm{CH}_{2} \mathrm{CHOH}^{+}$, is also reactive towards $i-\mathrm{PrOH}\left(k \sim 10^{-9} \mathrm{~cm}^{3} / \mathrm{mol}\right.$ ecule-s). The only reaction product which can be uniquely assigned to this precursor is $m / e$ 62, which must have the empirical formula $\mathrm{C}_{2} \mathrm{H}_{6} \mathrm{O}_{2}^{+}$. The production of this ion may correspond to an overall process involving elimination of $\mathrm{C}_{3} \mathrm{H}_{6}$ from the collision complex and the concurrent formation of the ethylene glycol molecular ion, $\left(\mathrm{CH}_{2} \mathrm{OH}\right)_{2}^{+}$, although other plausible structures for $\mathrm{C}_{2} \mathrm{H}_{6} \mathrm{O}^{+}$may also be written. The products resulting from the interactions of $m / e 60$ (parent ion) and $m / e 59$ (parent minus H) could not be determined from our data due to the low relative abundance of these ions in the primary mass spectrum.

\subsection{Reactions Occurring at Higher Pressures}

At pressures $\geqslant$ approximately 0.7 millitorr the appearances of $m / e 121,(i-\mathrm{PrOH})_{2} \mathrm{H}^{+}$and $m / e$ 103, $(i \text { - } \mathrm{PrOH})_{2} \mathrm{H}^{+}$minus $\mathrm{H}_{2} \mathrm{O}$ [most likely protonated diisopropyl ether $\left.(i-\mathrm{Pr})_{2} \mathrm{OH}^{+}\right]$are first noted. These products result from the further interactions of $(i-\mathrm{PrOH}) \mathrm{H}^{+}$ as follows:

$$
(i-\mathrm{PrOH}) \mathrm{H}^{+}+i \cdot \mathrm{PrOH} \rightarrow(i-\mathrm{PrOH})_{2} \mathrm{H}^{+}
$$

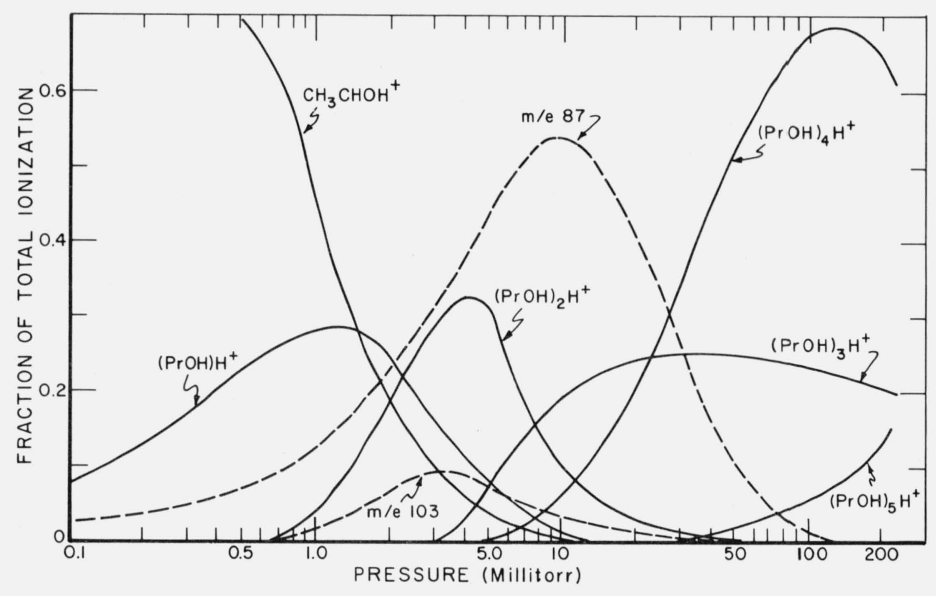

FIGURE 1. Composite mass spectrum obtained (major ions only) when i-PrOH is photoionized at 106.7-104.8 $\mathrm{nm}(11.7 \mathrm{eV})$ as a function of pressure. 


\section{$(i-\mathrm{PrOH}) \mathrm{H}^{+}+i-\mathrm{PrOH} \rightarrow(i-\mathrm{PrOH})_{2} \mathrm{H}^{+*}$}

$$
\rightarrow(i-\mathrm{Pr})_{2} \mathrm{OH}^{+}+\mathrm{H}_{2} \mathrm{O} \Delta H=-8 .
$$

Overall dehydration processes analogous to 6 have been observed mass spectrometrically in methanol [8] and ethanol [9] as well as $i$-PrOH [1a].

As the pressure in the reaction chamber is increased above 2-3 millitorr a number of higher order solvation reactions are observed yielding ionic products which will be designated simply as $(i-\mathrm{PrOH})_{3} \mathrm{H}^{+},(i-\mathrm{PrOH})_{4} \mathrm{H}^{+}$, and $(i-\mathrm{PrOH})_{5} \mathrm{H}^{+}$with the experimental order of appearance matching the apparent proton solvation number. Although the exact kinetic order of the various processes leading to the formation of these entities cannot be defined from our data due to the indeterminate effect of nonreactive scattering of ions at higher pressures, several general comments concerning the behavior under these conditions are warranted.

a. The fractional yield of $m / e 103(i-\mathrm{Pr})_{2} \mathrm{OH}^{+}$, exhibits a maximum at approximately 3 millitorr, which is slightly below the maximum found for $(i-\mathrm{PrOH})_{2} \mathrm{H}^{+}$ (see fig. 1). In addition, there is no evidence over the entire pressure range for the formation of $m / e 163$, which would be the product ion obtained if $m / e 103$ was removed via simple addition of a molecule of $i-\mathrm{PrOH}$. These observations may be taken as evidence for collisional stabilization of those internally excited $(i-\mathrm{PrOH})_{2} \mathrm{H}^{+}$entities which dissociate according to process 6 (loss of $\mathrm{H}_{2} \mathrm{O}$ ) at lower pressures. An alternative process for removal of $(i \text {-Pr })_{2} \mathrm{OH}^{+}$, bimolecular proton transfer to $i$ - $\mathrm{PrOH}$

$$
\begin{aligned}
(i-\mathrm{Pr})_{2} \mathrm{OH}^{+}+i-\mathrm{PrOH} \rightarrow & (i-\mathrm{PrOH}) \mathrm{H}^{+} \\
& +(i-\mathrm{Pr})_{2} \mathrm{O} \quad \Delta H=+12
\end{aligned}
$$

is endothermic as written for ground state reactants by approximately $12 \mathrm{kcal} / \mathrm{mol}$. However, the overall exothermicities of the two consecutive reactions responsible for production of $(i-\mathrm{Pr})_{2} \mathrm{OH}^{+}$, process $4 \mathrm{a}$ followed by process 6 , are exothermic by 13 and 8 $\mathrm{kcal} / \mathrm{mol}$ respectively, and we cannot rule out the possibility that the $(i-\operatorname{Pr})_{2} \mathrm{OH}^{+}$ion retains sufficient internal energy to overcome the energy barrier for reaction 7 . In any event, the overall process

$$
(i-\mathrm{Pr})_{2} \mathrm{OH}^{+}+2 i-\mathrm{PrOH} \rightarrow(i-\mathrm{Pr})_{2} \mathrm{O}+(i-\mathrm{PrOH})_{2} \mathrm{H}^{+}
$$

will certainly be exothermic as written due to the change in the solvation energy of $\mathrm{H}^{+}$when two molecules of $i$-PrOH are involved. Although the bimolecular reaction involving one $i$ - $\mathrm{PrOH}$ molecule is endothermic (process 7), an adequate quantity of additional energy is provided by the solvation reaction process

$$
(i-\mathrm{PrOH}) \mathrm{H}^{+}+i-\mathrm{PrOH} \rightarrow(i-\mathrm{PrOH})_{2} \mathrm{H}^{+} .
$$

Processes analogous to 8 have been reported from this laboratory for a number of polar systems [10]. b. The fractional yield of $m / e 87,(\mathrm{Me})(i-\mathrm{Pr}) \mathrm{COH}^{+}$, reaches a maximum at approximately 10 millitorr and decreases at higher pressures. Again, as in the previous case, the bimolecular proton transfer reaction

$$
\begin{aligned}
(\mathrm{Me})(i-\mathrm{Pr}) \mathrm{COH}^{+}+i-\mathrm{PrOH} \rightarrow(i-\mathrm{PrOH}) \mathrm{H}^{+} & \\
& +(\mathrm{Me})(i-\mathrm{Pr}) \mathrm{C}=\mathrm{O} \Delta H=+10
\end{aligned}
$$

is endothermic as written for ground state reactants by approximately $10 \mathrm{kcal} / \mathrm{mol}$. However, the process responsible for production of $m / e 87$ (process $4 \mathrm{~b}$ ) is exothermic by $38 \mathrm{kcal} / \mathrm{mol}$, and the possibility exists that retention of internal energy in the ionic reaction product is sufficient to drive the process to completion. Overall processes analogous to process 8 involving two molecules of $i-\mathrm{PrOH}$ will always be exothermic for ground state reactants. The appearance of $\mathrm{m} / \mathrm{e} 147$, which corresponds to the solvation of $m / e 87$ with one molecule of $i$-PrOH, was also noted at pressures above 5 millitorr.

c. At pressures in excess of 20 millitorr the major ionic species present in the system are $(i-\mathrm{PrOH})_{3} \mathrm{H}^{+}$, $(i-\mathrm{PrOH})_{4} \mathrm{H}^{+}$, and, at much higher pressures, $(i-\mathrm{PrOH})_{5} \mathrm{H}^{+}$. If one applies the empirical rule originally proposed by Munson [11] stating that the maximum proton solvation number in a system which can form hydrogen bonds will usually be one more than the number of hydrogens bonded to the heteratom, then one would expect the solvation number for the most stable structure in $i$-PrOH to be three. Assuming the validity of this empiricism, which does appear to be valid at least for the solvation reactions occurring in the methylamines [12], the observation in this study of $(i-\mathrm{PrOH})_{4} \mathrm{H}^{+}$and $(i-\mathrm{PrOH})_{5} \mathrm{H}^{+}$suggests that $(i-\mathrm{PrOH})_{3} \mathrm{H}^{+}$rearranges to give isomeric alcohols or ketones which can readily incorporate additional solvent molecules. It is interesting to note in this context that the fractional yield of $(i-\mathrm{PrOH})_{3} \mathrm{H}^{+}$, the anticipated stable form, decreases in relative abundance much more slowly as a function of pressure than $(i-\mathrm{PrOH}) \mathrm{H}^{+},(i-\mathrm{PrOH})_{2} \mathrm{H}^{+}$, and $(i-\mathrm{PrOH})_{4} \mathrm{H}^{+}$. However, whether or not this apparent reduction in reactivity is associated with the stability of the unrearranged trisolvated form cannot be ascertained from our data.

\section{Discussion}

\subsection{Implications for the Radiolysis of Isopropanol}

The vapor phase radiolysis of $i$-PrOH has been reported by Van der Linde and Freeman [2] from 125 to $400{ }^{\circ} \mathrm{C}$ and over a range of pressures from 100 to 2000 torr. The significant result of their study was evidence for production of diisopropyl ether, $(i-\mathrm{Pr})_{2} \mathrm{O}$, via a chain mechanism. Energy $(G)$ values as high as 1000 were obtained under certain conditions, and the overall chain length was found to increase with increasing temperature and decreasing pressure. In order to account for their findings a cationic chain mechanism was proposed having as an initiation step a bimolecular proton transfer reaction involving the parent molecular ion 


$$
i-\mathrm{PrOH}^{+}+i \cdot \mathrm{PrOH} \rightarrow(i-\mathrm{PrOH}) \mathrm{H}^{+}+\mathrm{C}_{3} \mathrm{H}_{7} \mathrm{O}^{+} .
$$

It was suggested that process was followed by conversion of $(i-\mathrm{PrOH}) \mathrm{H}^{+}$into $(i-\mathrm{PrOH})_{n} \mathrm{H}^{+}$via successive collisions, with the rate controlling step in the chain mechanism corresponding to process 6

$$
\begin{aligned}
(i-\mathrm{PrOH}) \mathrm{H}^{+} & +i-\mathrm{PrOH} \rightarrow(i-\mathrm{PrOH})_{2} \mathrm{H}^{+*} \\
& \rightarrow(i-\mathrm{Pr})_{2} \mathrm{OH}^{+}+\mathrm{H}_{2} \mathrm{O} \quad \Delta H=-8 .
\end{aligned}
$$

The mechanism for production of neutral $(i \text { - } \mathrm{Pr})_{2} \mathrm{O}$, as well as the subsequent reactions of $(i-\mathrm{Pr})_{2} \mathrm{OH}^{+}$, was not specified.

Although it is difficult to extrapolate the behavior observed in our experiments, which were carried out at $298 \mathrm{~K}$, to that characteristic of temperatures in the range 400 to $700 \mathrm{~K}$, our data does suggest a possible cationic chain for production of $(i-\mathrm{Pr})_{2} \mathrm{O}$ which is consistent with the radiolysis results. The formalism follows.

It is evident that the role of parent molecular ions, $i$ - $\mathrm{PrOH}^{+}$, will be negligible at temperatures above $400 \mathrm{~K}$ due to the fact that the activation energy for dissociation is on the order of only $0.15 \mathrm{eV}$ [6]. Although the exact identities and relative yields of the various fragment ions produced under radiolysis conditions cannot be specified, consideration of the fragmentation pattern of $i-\mathrm{PrOH}$ produced both by high energy electron impact [13] and photoionization [6] over a wide range of temperatures indicates that the major ionic species present initially will most probably be $\mathrm{CH}_{3} \mathrm{CHOH}^{+}$(the major ion in our study) with smaller contributions from $\mathrm{C}_{2} \mathrm{H}_{3}^{+}, \mathrm{C}_{3} \mathrm{H}_{7}^{+}, \mathrm{C}_{2} \mathrm{H}_{5}^{+}$, etc., as well as fragments containing oxygen atoms. Most, if not all, of the primary ions will react via proton transfer with parent molecules at higher temperatures

$$
\mathrm{XH}^{+}+i-\mathrm{PrOH} \rightarrow(i-\mathrm{PrOH}) \mathrm{H}^{+}+\mathrm{X}
$$

$\left(\mathrm{XH}^{+}\right.$denotes any of the primary fragment ions).

Under radiolysis conditions, the $(i-\mathrm{PrOH}) \mathrm{H}^{+}$ions so formed will rapidly initiate a series of sequential, competing processes including reactions 5,6 , and 8 . Since cationic production of $(i-\mathrm{Pr})_{2} \mathrm{O}$ must be related to the formation of $(i-\mathrm{Pr})_{2} \mathrm{OH}^{+}$, which is in turn related exclusively to the decomposition of internally excited $(i-\mathrm{PrOH})_{2} \mathrm{H}^{+}$, it follows that the rate controlling step in any chain mechanism must involve the competition between process 6 and the conversion of $(i$ $\mathrm{PrOH})_{2} \mathrm{H}^{+}$into more highly solvated (or rearranged) ions which cannot yield $(i-\mathrm{Pr})_{2} \mathrm{OH}^{+}$as a decomposition product. Once formed, $(i-\mathrm{Pr})_{2} \mathrm{OH}^{+}$ions will be quickly converted to $(i-\mathrm{Pr})_{2} \mathrm{O}$ via either

$$
\begin{array}{r}
(i-\mathrm{Pr})_{2} \mathrm{OH}^{+}+i-\mathrm{PrOH} \rightarrow(i-\mathrm{PrOH}) \mathrm{H}^{+}+(i-\mathrm{Pr})_{2} \mathrm{O} \\
\Delta H=+12
\end{array}
$$

or

$$
(i-\mathrm{Pr})_{2} \mathrm{OH}^{+}+2 i-\mathrm{PrOH} \rightarrow(i-\mathrm{Pr})_{2} \mathrm{O}+(i-\mathrm{PrOH})_{2} \mathrm{H}^{+} .
$$

According to this mechanism, the chain carrier is either $(i-\mathrm{PrOH}) \mathrm{H}^{+}$or $(i-\mathrm{PrOH})_{2} \mathrm{H}^{+}$. The fact that $\mathrm{Van}$ der Linde and Freeman [2] observed a substantial decrease in the yields of $(i-\mathrm{Pr})_{2} \mathrm{O}$ at higher pressures (temperature held constant) is consistent with this sequence since collisional deactivation of $(i-\mathrm{PrOH})_{2} \mathrm{H}^{+}$ or further solvation of this ion prior to dissociation will be favored at higher densities. Alternatively, an increase in temperature at constant pressure will serve to increase the rate of dissociation of $(i-\mathrm{PrOH})_{2} \mathrm{H}^{+}$ into $(i-\mathrm{Pr})_{2} \mathrm{OH}^{+}$.

\subsection{Some Comments on the Proton Affinity of $\mathrm{SF}_{6}$}

Van der Linde and Freeman [2] also reported a number of experiments involving the radiolysis of $i$-PrOH-additive mixtures. The additives included $\mathrm{H}_{2} \mathrm{O}, \mathrm{C}_{3} \mathrm{H}_{6}, \mathrm{SF}_{6},\left(\mathrm{CH}_{3}\right)_{2} \mathrm{CO}$, and $\mathrm{NH}_{3}$, all of which inhibited ether formation to some extent. These authors concluded, on the basis of a plot of the proton affinity of the additive versus the ether yield, that the proton affinity of $\mathrm{SF}_{6}$ was on the order of $184 \mathrm{kcal} / \mathrm{mol}$. The absolute value for the proton affinity of $\mathrm{SF}_{6}$ is an important quantity for kineticists since this molecule is used extensively as a thermal electron scavenger in ionized systems in order to modify the charge neutralization mechanism [14]. In order to offer an independent measurement of this quantity we have carried out several additional experiments. An upper limit for the proton affinity of $\mathrm{SF}_{6}$ may be estimated by determining whether or not a hypothetical ion $\mathrm{MH}^{+}$ (in which the proton affinity of $M$ is known) will undergo the following reaction

$$
\begin{gathered}
\mathrm{MH}^{+}+\mathrm{SF}_{6} \rightarrow \mathrm{SF}_{6} \mathrm{H}^{+} \text {(or dissociative proton transfer } \\
\text { products }+\mathrm{M} \text {. }
\end{gathered}
$$

A series of possible proton donors $\left(\mathrm{MH}^{+}\right)$were investigated via photoionization of $\mathrm{SF}_{6}$-hydrocarbon mixtures at $11.7 \mathrm{eV}$, since at this energy ionization occurs only in the hydrocarbon component (I.P. SF ${ }_{6}$ $=15.3 \mathrm{eV})$. Although the results will not be presented in detail, we were unable to find any evidence for the occurrence of process 12 for $\mathrm{MH}^{+}$ions in which the proton affinity of $M$ was as low as $146 \mathrm{kcal} / \mathrm{mol}$ (the lower limit available to us as a possible reactant). This limit was established by determining that the reaction

$$
\mathrm{C}_{2} \mathrm{H}_{6}^{+}+\mathrm{SF}_{6} \rightarrow \mathrm{C}_{2} \mathrm{H}_{5}+\mathrm{SF}_{6} \mathrm{H}^{+}
$$

did not occur for ground state reactants, and assuming a value of $146 \mathrm{kcal} / \mathrm{mol}$ for the proton affinity of $\mathrm{C}_{2} \mathrm{H}_{5}$. Since this general method has been used successfully in several laboratories [7b] to establish limits for proton affinities, we are forced to conclude that the proton affinity of $\mathrm{SF}_{6}$ is less than $146 \mathrm{kcal} / \mathrm{mol}$ and that the assumptions of Van der Linde and Freeman [2] are in error. An upper limit of this magnitude indicates that the addition of $\mathrm{SF}_{6}$ will not materi- 
ally effect the positive ion chemistry occuring in hydrocarbons during radiolysis.

In order to resolve what effects the addition of $\mathrm{SF}_{6}$ to $i$-PrOH might have had in the radiolysis study we also carried out a number of experiments in which various $i$ - $\mathrm{PrOH}-\mathrm{SF}_{6}$ mixtures were photoionized at $11.7 \mathrm{eV}$ over the pressure range covered by figure 1. Again (all of the results were negative in the sense that) we were unable to detect any reaction between $\mathrm{SF}_{6}$ and any of the ions resulting from the photoionization of $i$ - $\mathrm{PrOH}$, including higher molecular weight products such as $(i-\mathrm{PrOH})_{2} \mathrm{H}^{+},(i-\mathrm{PrOH})_{3} \mathrm{H}^{+},(i-\mathrm{Pr})_{2} \mathrm{OH}^{+}$, etc. This finding is consistent with the general assumption that $\mathrm{SF}_{6}$ exhibits an extremely low reactivity towards positive ions, and on this basis we cannot offer any rationale for the effects observed in the radiolysis experiments.

We are indebted to P. Ausloos for his advice and counsel during the course of this study.

\section{References}

[la] Beauchamp, J. L., and Dunbar, R. C., J. Am. Chem. Soc. 92 , $1477(1970)$

[1b] Lehman, T. A., Elwood, T. A., Bursey, J. T., Bursey, M. M., and Beauchamp, J. L., ibid, 93, 2108 (1971).

[2] Van der Linde, H. J., and Freeman, G. R., J. Am. Chem. Soc. 92, 4417 (1970).

[3a] Sieck, L. W., and Ausloos, P., J. Chem. Phys. 56, 1010 (1972).

[3b] Sieck, L. W., and Ausloos, P., J. Res. Nat. Bur. Stand. (U.S.), 76A (Phys. and Chem.), No. 3, 253-262 (May-June 1972). [3c] Sieck, L. W., Searles, S., and Ausloos, P., J. Chem. Phys. 54, 91 (1971).

[3d] Searles, S. K., Sieck, L. W., and Ausloos, P., ibid, 53, 849 (1970).

[4] Sieck, L. W., Searles, S. K., and Ausloos, P., J. Am. Chem. Soc. 91, 7627 (1969).

[5] Sieck, L. W., and Searles, S. K., J. Am. Chem. Soc. 92, 2937 (1970).

[6] Rafaey, K. M. A., and Chupka, W. A., J. Chem. Phys. 48, 5205 (1968).

[7] Overall heats of reaction are calculated from thermodynamic data contained in the following publications:

[7a] Franklin, J. L., Dillard, J. L., Rosenstock, H. M., Herron, J. T., Draxl, K., and Field, F. H., Nat. Stand. Ref. Data Ser., Nat. Bur. Stand. (U.S.), 26, 289 pages (June 1969).

[7b] Beauchamp, J. L., Ann. Rev. Phys. Chem. 22, 527 (1971).

[7c] Ausloos, P., and Lias, S. G., Radiation Chemistry of Organic Compounds. Ionic Processes (M. I. T. Press (U.S.), 1972).

[8a] Munson, M. S. B., J. Am. Chem. Soc. 87, 5313 (1965).

[8b] Henis, J. M. S., ibid, 90, 844 (1968).

[9] Sieck, L. W., Futrell, J. H., and Abramson, F. P., J. Chem. Phys. 45, 2859 (1966).

[10a] Hellner, L., and Sieck, L. W., J. Res. Nat. Bur. Stand. (U.S.), 75A (Phys. and Chem.), No. 5, 487-492 (September-October 1971).

[10b] Sieck, L. W., and Searles, S. K., J. Chem. Phys. 53, 2601 (1970).

[11] Munson, M. S. B., J. Phys. Chem. 70, 2034 (1966).

[12] Hellner, L., and Sieck, L. W., Int. J. Chem. Kinetics, in press.

[13] Friedman, L., Long, F. A., and Wolfsberg, M., J. Chem. Phys. 27,613 (1957). and references cited therein.

[14] See, for example, Fundamental Processes in Radiation Chemistry, P. Ausloos, Ed. (John Wiley \& Sons, Inc., New York, N. Y., 1968).

(Paper 76A6-749) 